The Special Session on Military Medicine will be comprised of two parts. The first presentation will outline how the new specialty of Military Medicine has been developed in Ireland, and give details on the modules, competencies and learning outcomes of the specialist training programme. The second presentation will provide an insight into the experiences of the Irish Naval Service involved in the ongoing operational deployment to assist in the Mediterranean refugee crisis, and look at some of the occupational medicine implications of this deployment.

Presenters: ${ }^{1}$ Lt Col Dr John Paul Hickey, ${ }^{2}$ Lt Cdr Anthony Geraghty

${ }^{1}$ Faculty of Military Medicine of Ireland (FMMI), Dublin, Ireland

${ }^{2}$ Naval Service Defence Forces Ireland, Cork, Ireland

\section{6a EXPLORING NEW FRONTIERS IN MEDICAL TRAINING: A JOURNEY THROUGH THE DEVELOPMENT AND LAUNCH OF THE HIGHER SPECIALIST TRAINING PROGRAMME IN MILITARY MEDICINE}

JP Hickey. Faculty of Military Medicine of Ireland (FMMI), Dublin, Ireland

\subsection{6/oemed-2018-ICOHabstracts. 1069}

In July 2017 the Irish Medical Council formally recognised and accredited a new and innovative higher specialist training programme in Military Medicine. The development of this programme was a collaborative project between the Irish College of General Practitioners (ICGP) and the Faculty of Military Medicine Ireland (FMMI). It represents a marriage between the traditional vocational General Practice training pathway combined with a tranche of multi-faceted Military Medicine specific modules, including occupational medicine, designed to competently equip medical practitioners for military service at home and overseas. This dual-specialist training programme, a formal and recognised medical qualification encompassing Military Medicine and General Practice training, is the first of its kind anywhere in the world. This collaboration and the development of the training programme represent the very essence of innovation and forward-thinking in medical education. Military Medicine involved the coming together of a wide number of disparate groups and multi-organisational cooperation to bring this specialty from concept to reality. Through this presentation I will outline the journey from project foundation to specialty recognition leading to the induction of the first trainees onto the specialist training programme on the 10th of July 2017.

\section{6b NAVAL SERVICE OPERATIONS IN THE MEDITERRANEAN: A MEDICAL BATTLEFIELD?}

A Geraghty. Irish Naval Service, Haulbowline, Cork, Ireland

10.1136/oemed-2018-ICOHabstracts. 1070

Since early 2015 the Irish state has been deploying Naval Ships to the Mediterranean to conduct humanitarian search and rescue operations in order to assist with the migrant crisis. Three ships are rotated per year and as of 23 Oct Oct 2017, the Irish Naval Service have rescued 17404 migrants, dealt with seventy-eight fatalities and delivered two babies onboard their ships. The scale of the operation is unprecedented for any ship, as are the harsh realities of fatalities, and the shock of delivering a baby onboard a warship. In his presentation, Lt Cdr Geraghty provides an overview of the region, discusses the actors operating in the region. $\mathrm{He}$ then describes Irish Naval Service operations along with an overview of medical services provided. Finally, he presents four case studies where he describes: a typical day rescuing migrants, the delivery of a baby by an EMT, a mass casualty event where between 200 and 300 people drowned in front of a ship, and finally he describes how ship crews have to deal with decomposing bodies in sweltering heat. In his presentation Lt Cdr Geraghty argues that, as a battlefield is 'a place or situation of strife or conflict', Irish Naval Ships are operating in a medical battlefield. This unique working environment has presented many challenges to the occupational medicine service delivered to the crew of the Irish Naval Ships.

\section{SENTINEL AND ALERT SYSTEMS IN OCCUPATIONAL MEDICINE (MODERNET)}

${ }^{1}$ Lode Godderis, ${ }^{2}$ Tim Driscoll. ' KU Leuven, Centre for Environment and Health, Leuven, Belgium; ${ }^{2}$ Sydney School of Public Health, Sydney, Australia

\subsection{6/oemed-2018-ICOHabstracts.1071}

Aim of special session Continuous changes in work are followed by the rise of new occupational health risks and possibly new work-related diseases, which remain difficult to detect and prevent. Hence, new agents are constantly being introduced at the workplace, with no clear assessment of long-term health risks. Consequently, the detection of new occupational risks requires specific additional instruments to those already in use for monitoring known work-related diseases. The method of choice might be influenced by the type of disease and its prevalence in the (risk) population. In the case of a rare disease with a high etiological fraction, spontaneous reporting by a large group of physicians or workers in a sentinel or alert system would be a good monitoring instrument. These alert systems can forecast and signal adverse effects on health, providing time for response in order to minimalize their impact.

Presenters: Jelena Bakusic1, Annet Lenderink2, Stefania Curti3

${ }^{1} \mathrm{KU}$ Leuven, Centre for Environment and Health, Leuven, Belgium

${ }^{2}$ Netherlands Centre for Occupational Diseases, Amsterdam, Netherlands

${ }^{3}$ Department of Medical and Surgical Sciences, University of Bologna, Bologny, Italy

\section{6a OVERVIEW ON SENTINEL AND ALERT SYSTEMS IN OCCUPATIONAL MEDICINE}

${ }^{1}$ Jelena Bakusic*, ${ }^{2}$ Annet Lenderink, ${ }^{1,3}$ Sofie Vandenbroeck, ${ }^{1,3}$ Charlotte Lambreghts, ${ }^{4}$ Jos Verbeek, ${ }^{5}$ Stefania Curti, ${ }^{5}$ Stefano Mattioli, ${ }^{1,3}$ Lode Godderis. ${ }^{1}$ Environment and Health, KU Leuven, Belgium; ${ }^{2}$ Coronel Institute of Occupational Health, AMC/University of Amsterdam, The Netherlands; ${ }^{3} I D E W E$, External Service for Prevention and Protection at Work, Heverlee, Belgium; ${ }^{4}$ Cochrane Work Review Group, Finnish Institute of Occupational Health, Kuopio, Finland; ${ }^{5}$ Department of Medical and Surgical Sciences, University of Bologna, Bologna, Italy

10.1136/oemed-2018-ICOHabstracts. 1072 
Objective Changes in working conditions give rise to new occupational health risks and work-related diseases (WRDs). Monitoring these new WRDs is essential for their early recognition and prevention and requires a comprehensive approach, using several complementary methods. The aim of this review is to provide an overview and basic typology of different approaches to detect new/emerging WRDs.

Methods We conducted an extensive scientific literature search combining terms for the following three concepts:

- surveillance/reporting systems;

- occupational/work-related diseases; and

- new or emerging risks. In addition, a grey literature search was performed of both grey literature databases and relevant EU and research institute websites for additional resources.

Results We identified a total of 75 surveillance systems from 26 different countries. We set up a basic typology of these systems dividing them into four main groups. Compensationbased systems $(n=22)$ were designed to gather data for compensation purposes and are insurance-driven. Non-compensation-related systems $(n=34)$ were created with the aim of improving the collection and analysis of data to measure trends in occupational and work-related diseases. Sentinel systems $(n=12)$ were specifically designed to provide a warning signal that will initiate health interventions and preventive actions. Finally, public health surveillance systems $(n=7)$ aim to monitor the health of the general population, but can also be used for work-related surveillance. These four main types further differed in terms of disease coverage, means of data collection, evaluation of work-relatedness, follow-up of new/ emerging risks, link with prevention etc.

Conclusion Sentinel systems seem to have the most suitable approach to detect and alert to new/emerging WRDs. Nevertheless, systems identified in the other three groups can also contribute to identifying new/emerging WRDs, despite being primarily designed for other purposes.

\section{6b LESSONS LEARNED FROM EXISTING SENTINEL AND ALERT SYSTEMS}

${ }^{1}$ Annet Lenderink*, ${ }^{2}$ Jelena Bakusic, ${ }^{2}$ Sofie Vandenbroeck, ${ }^{2}$ Charlotte Lambreghts, ${ }^{2}$ Lode Godderis. ${ }^{1}$ Netherlands Centre for Occupational Diseases, Coronel Institute on Work and Health, AMC/University of Amsterdam, Netherlands; '2KULeuven, Occupational, Environmental and Insurance Medicine. Leuven, Belgium

\subsection{6/oemed-2018-ICOHabstracts. 1073}

Introduction Drawing on a literature review on sentinel and alert systems for identifying new/emerging work-related diseases (WRDs) a basic typology of systems was developed. These systems differ in characteristics, ability to capture new WRDs and link with prevention. The objectives of the subsequent study of a subset of systems were to describe in-depth aims, drivers and obstacles of the systems and use of their data in practice, for prevention and detecting new/emerging WRDs.

Methods Twelve systems were chosen reflecting the different types (linked to compensation or not, aimed at all WRDs or a subset of diseases, sentinel systems, workers only or general public). Six systems were described based on desk research and six other systems were studied through interviews with different actors to gather information on the operation of the systems and the use of the gathered data for prevention.

Results Several important themes emerged from the comparative tables, related to the design and performance of the system: visibility, reporting methods, exposure assessment, data quality, linkage to other institutions, and related to data use for prevention, alert on hazardous situations, and awareness on new/emerging diseases.

Conclusion Each system has its strengths and limitations, closely related to its purpose and the country that developed it. Sentinel systems seem to be best equipped for prevention and alert on new/emerging diseases. Enhancing reporting needs to balance required information and perceived reward for reporters. Embedding of systems in governmental or public health organisations is important in terms of financing, expertise and dissemination of results.

\section{C MAREL: THE ITALIAN NETWORK ON WORK-RELATED DISEASES}

${ }^{1} \mathrm{~S}$ Curti* ${ }^{*},{ }^{1} \mathrm{~S}$ Mattioli, ${ }^{2} \mathrm{P}$ Cocco, ${ }^{3} \mathrm{~A}$ Cristaudo, ${ }^{4} \mathrm{M}$ dell'Omo, ${ }^{5} \mathrm{G}$ Mosconi, ${ }^{6} \mathrm{G}$ Campo. ${ }^{1}$ Department of Medical and Surgical Sciences, University of Bologna, Italy; ${ }^{2}$ Department of Public Health, Clinical and Molecular Medicine, University of Cagliari, Italy; ${ }^{3}$ Unit of Occupational Medicine, University of Pisa, Italy; ${ }^{4}$ Unit of Occupational and Environmental Medicine, Department of Medicine, University of Perugia, Italy; ${ }^{5}$ Unit of Occupational Medicine, Azienda Ospedaliera Papa Giovanni XXIII, Bergamo, Italy; ${ }^{6}$ Department of Work and Environmental Medicine, Epidemiology and Hygiene, National Institute for Insurance against Accidents at Work (INAIL), Rome, Italy

\subsection{6/oemed-2018-ICOHabstracts. 1074}

Introduction To study new disease-exposure associations, we created a pilot network (namely MAREL - MAlattie e Rischi Emergenti sul Lavoro) of occupational disease consultation centres of the Italian national health service to which patients are referred for potentially work-related diseases.

Methods The MAREL network included in 2016 five occupational disease consultation centres of university hospitals located in central-northern Italy. Patients were referred to the MAREL consultation centres by their general practitioners, occupational physicians or other specialists for the investigation of the putative occupational origin of a disease. Each centre collected cases of putative occupational origin through a structured and standardised data collection form. We collected data on: diagnosis; personal habits; occupational history; exposure to risk factors; physician's opinion on the possible causal relationship between disease and occupation. Data were coded according to national and international classifications.

Results The data collection started in 2016, enrolling 1516 cases of putative occupational diseases. Musculoskeletal disorders were the most represented conditions: intervertebral lumbar disc degeneration $(11.2 \%)$, spondylitis $(6.3 \%)$, tendinopathies $(4.9 \%)$, arthritis (4.8\%), upper limb mononeuropathies (4.4\%), and shoulder disorders (3.7\%). The most frequently reported exposures were related to biomechanical overload: manual material 